\title{
Early Sexual Initiation and Associated Factors among Debre Markos University Students, North West Ethiopia
}

\author{
Getachew Mullu Kassa ${ }^{1, *}$, Girmay Tsegay ${ }^{2}$, Nurilign Abebe², Woldie Bogale², Teferi Tadesse', \\ Desalegne Amare ${ }^{3}$, Girma Alem ${ }^{3}$
}

${ }^{1}$ Midwifery Department, Medicine and Health Sciences College, Debre Markos University, Debre Markos, Ethiopia

${ }^{2}$ Public Health Officer Department, Medicine and Health Sciences College, Debre Markos University, Debre Markos, Ethiopia

${ }^{3}$ Nursing Department, Medicine and Health Sciences College, Debre Markos University, Debre Markos, Ethiopia

\author{
Email address: \\ gechm2005@gmail.com (G. Mullu),girmshe@gmail.com(G. Tsegay), nure113@gmail.com (N. Abebe), \\ woldie.bogale@gmail.com (W. Bogale), teferi.tadesse@gmail.com (T. Tadesse), desa2001@yahoo.com (D. Amare), \\ girmaalem95@gmail.com (G. Alem)
}

\section{To cite this article:}

Getachew Mullu Kassa, Girmay Tsegay, Nurilign Abebe, Woldie Bogale, Teferi Tadesse, Desalegne Amare, Girma Alem. Early Sexual Initiation and Associated Factors among Debre Markos University Students, North West Ethiopia. Science Journal of Clinical Medicine. Vol. 4, No. 5, 2015, pp. 80-85. doi: 10.11648/j.sjcm.20150405.11

\begin{abstract}
Background: Sexual activities during adolescence have been characterized as dynamic and constantly changing, and it has an impact on reproductive life of young peoples, which is related to the increased susceptibility to HIV transmission, unwanted pregnancy and its complications when the sexual activities are unprotected. So, the objective of this study was to identify the prevalence of early sexual initiation and its associated factors among Debre Markos University students, North West Ethiopia, 2014. Methods: Institution based cross sectional study design was conducted among 273 Debre Markos university students. Study participants were selected by stratified sampling technique and self- administrated questionnaire was distributed to collect information. EpiData version 3.1 was used for data entry and SPSS version 16 was used for analysis. To identify factors associated with sexual initiation, bivariate and multivariate logistic regression with $95 \%$ Confidence interval was used. Results: From 260 respondents, 116(44.6\%) had sex prior to the data collection period, while 144(55.4\%) had never had sexual intercourse. Almost two third (64.7\%) of respondents start sexual intercourse during the age range of 16-19 years old. The mean and standard deviation for the age at first sex was 18.28 and 2.04 years respectively. Factors which were significantly associated with early sexual initiation ( $<18$ years old) were; being female $(\mathrm{AOR}=5.7,95 \% \mathrm{CI}=1.16-27.72)$, lack of discussion on sexual and reproductive health issues $(\mathrm{SRH})$ with their mother $(\mathrm{AOR}=, 95 \% \mathrm{CI}=1.23-41.5)$ and cigarrate smoking $(\mathrm{AOR}=7$, $95 \% \mathrm{CI}=1.06-46.92)$. Conclusions: Early sexual initiation was high. Factors which were associated with early sexual initiation were being female, lack of discussion on SRH with mother and cigarrate smoking. So, awareness creation for both male and female young peoples through the use of religious leaders, school teachers and parents on sexual and reproductive health issues is important. Young peoples should be encouraged to discuss with their parents on SRH through the use of reproductive health centers and emphasis should also be given for adolescents who use drugs like cigarrate smoking.
\end{abstract}

Keywords: Sexual Initiation, Early Sexual Activity, Debre Markos University, Students

\section{Background}

Early Sexual initiation during adolescent period has several potential impacts on reproductive life of young peoples. Youth who begin early sexual activity are more likely to have high-risk sex and they are less likely to use condoms which is related to the increased susceptibility to HIV transmission and other STIs, unwanted pregnancy and it complications [1-5].

According to WHO 2007 report, 45\% of HIV new infection is among youths aged $15-49$, and $11 \%$ of all births worldwide is among adolescents [6]. In addition Sub-Sahara Africa was one of the most affected parts of the world with HIV/AIDS. According to WHO 2010 report Sub Saharan Africa has an estimated 22.9 million people living with HIV [7].

According to Ethiopian Demographic and Health Survey (EDHS) 2011 report 29 percent of women aged 25-49 had sexual intercourse before age 15, 62 percent before age 18, and by age 25, 88 percent had had sexual intercourse [8]. 
Researches showed that factors associated with sexual initiation among young peoples are age, gender, educational level, knowledge on HIV, communication on sexual and reproductive health issues, parental socio economic status, watching pornography, attitude towards premarital sex and substance abuse $[3,5,9,10-16]$.

\section{Methods}

\subsection{Study Area and Period}

The study was conducted in Amhara regional state, East Gojjam Zone, Debre Markos town among Debre Markos University (DMU) students. Debre Markos University is found in the Northwestern part of the country at Debre Markos town. The University is located in the Eastern part of the town approximately two kilometers from the central square. Debre Markos is located 300 kilometers North-West of the capital Addis Ababa and 265 kilometers South-East of Bahir Dar, the capital of the Amhara National Regional State [17, 18].

\subsection{Study Design and Population}

Institutional based cross sectional study was conducted. The source population of this study were all DMU regular students who were attending their education in 2014/15. The study population were the randomly selected regular students of DMU who were attending their education in 2014/15. Students who were seriously ill to respond to the questionnaire were excluded from the study.

\subsection{Sample Size Determination}

Single population proportion formula was used to calculate the sample size. Prevalence of sexual practice before marriage was considered to be 20.23 from a study conducted in Injibara [19]. In addition $95 \%$ CI, 5\% margin of error and $10 \%$ none response rate was considered.

To determine the sample size; the following formula was used

$$
\begin{gathered}
\mathrm{n}=(\mathrm{Za} / 2)^{2} \times \mathrm{P}(1-\mathrm{P}) / \mathrm{d}^{2} \\
\mathrm{n}=\left(1.96^{2} * 0.2023(1-0.2023) /(0.05)^{2}\right. \\
=0.614656 / 0.0025=247.87 \simeq 248
\end{gathered}
$$

By considering $10 \%$ none response rate, the final sample size was 273 .

\subsection{Sampling Procedure}

Stratified sampling and random sampling techniques were used to select study participants from the source population. To allocate the number of participants for each college/school, population proportion to sample size (PPS) was used.

\subsection{Data Collection and Quality Control}

Close ended self-administered questionnaire adapted from several researches was used for data collection [20, 21].
Pre-test was done on 5\% of the total sample size (14 students) in Debre Markos teacher college students, and necessary modification was done according to the result of the pretest. Two data collectors and 2 supervisors were participated in the data collection and training on data collection, and confidentiality issues was given one day prior and after the pretest for the data collectors. Informed consent was taken from the study participants prior to the data collection. Consistency and completeness of filled questionnaire was checked by supervisor every day.

\subsection{Study Variables}

The dependent variable for this study was sexual initiation (sexual initiation below or above 18 years old). The independent variables were; Socio Demographic variables (Age, Sex, Religiosity, Educational, Ethnicity, marital status); Parental education and occupation, Communication \& source of information about sexual and reproductive health issues, Attitude towards premarital sex, Substance abuse (alcohol, smoking of cigarate, chat, shisha), and Viewing of sexually explicit movies.

\subsection{Data Processing and Analysis}

Data was entered using EpiData version 3.1 and SPSS version 16 was used for analysis. Descriptive analysis was used using frequency and percentage. In addition, tables and figures were used to present the data. To assess the factors associated with early sexual initiation, Bivariate and multivariate analysis with $95 \%$ CI was computed. Variables with p-value less than 0.05 were considered to have significant association.

\subsection{Operational Definition}

Age at first sex: the first age in which the respondents start sexual intercourse.

Attitude: any subjective belief of the respondents associated with sexual activity.

Unfavorable attitude: respondents who answered below the mean of attitude towards sex related questions.

Favorable attitude: respondents who answered above the mean of attitude towards sex related questions.

Ethical consideration: Ethical clearance was obtained from DMU, College of Medicine and Health Science institutional review board. Permission was granted from all colleges and schools through the formal letter obtained from the College's research committee institutional review board. Respondents gave their willingness prior to filling the questionnaire.

\section{Results}

\subsection{Socio Demographic Characteristics of Respondents}

The study was conducted among Debre Markos University, from a total of 273 respondents, 260 respondents complete the questionnaire giving a response rate of $95.24 \%$. Majority, $180(69.2 \%)$ of respondents were males and $201(77.3 \%)$ of 
respondents were with age range of 20-24. The mean age and Standard Deviation of respondents were 21.91 and 2.24 respectively, with a minimum of 17 and maximum of 32 years old. Almost two third (63.5\%) of respondents were Amhara by ethnicity, and 208(80\%) were orthodox by religion. Majority, $78.5 \%$ of the respondents said that their living condition were with their father and mother, while only 5 respondents said that they were living alone before joining to university. Two hundred forty three $(93.5 \%)$ of respondents were never married while $17(6.5 \%)$ were ever married (currently married, divorced, or widowed) (Table 1).

Table 1. Socio demographic characteristics of respondents among Debre Markos University students, North West Ethiopia, 2014.

\begin{tabular}{llll}
\hline Variables & & Frequency & Percentage \\
\hline \multirow{2}{*}{ Sex } & Male & 180 & 69.2 \\
Age & Female & 80 & 30.8 \\
(Mean=21.91 & 17-19 years old & 29 & 11.2 \\
$\mathrm{SD}=2.24)$ & 25-24 years old & 201 & 77.3 \\
& $1^{\text {st }}$ year & 30 & 11.5 \\
& $2^{\text {nd }}$ year & 68 & 26.2 \\
Year of study & $3^{\text {rd }}$ year & 77 & 29.6 \\
& $4^{\text {th }}$ year & 98 & 37.7 \\
& $5^{\text {th }}$ year & 8 & 3.1 \\
& Amhara & 9 & 3.5 \\
Ethnicity & Oromo & 165 & 63.5 \\
& Tigray & 42 & 16.2 \\
& Afar, Gurage & 16 & 6.2 \\
Marital status & Never married & 37 & 14.2 \\
& Ever Married & 243 & 93.5 \\
& Orthodox & 17 & 6.5 \\
Religion & Muslim & 208 & 80 \\
& Protestant & 28 & 10.8 \\
& Others (Catholic, Pagan) & 10 & 5.4 \\
Living & Both Father and mother & 204 & 3.8 \\
condition & Either Mother or father & 35 & 78.5 \\
& Friends/Relatives & 16 & 13.5 \\
\hline & Alone & 5 & 6.2 \\
& & & 1.9 \\
\hline
\end{tabular}

\subsection{Parental Socio Economic Status}

Almost half $(48.8 \%)$ and $102(39.2 \%)$ of respondents father's and mother education respectively were college level and above. While majority of respondents father's, 107(41.2\%) and mother's, 81(31.2\%), occupation were civil servant and farmer respectively. Almost half, 129(49.6\%) of respondents family average monthly income were more than 1500 Ethiopian Birr (ETB) with minimum, maximum and median of 100, 9000, and 2000 ETB respectively (Table 2).

\subsection{Non Sexual Risk Behaviors}

About $215(82.7 \%)$ of respondents have never smoked cigarate, while $8(3.1 \%)$ smoke cigarate daily. In addition $187(71.9 \%)$ and $153(58.8 \%)$ of respondents said that they have never chew chat and never drank alcohol respectively. While $30(11.5 \%)$ of respondents chew chat daily and $13(5 \%)$ drunk alcohol daily. More than two third (67.3\%) of respondents said that they have never seen pornographic movies, while $85(32.7 \%$ ) have viewed pornographic movies, prior to the data collection period (Table 3 ).
Table 2. Parental socio economic characteristics of respondents among Debre Markos University students, North West Ethiopia, 2014.

\begin{tabular}{|c|c|c|c|}
\hline Variables & & Frequency & Percentage \\
\hline \multirow{6}{*}{$\begin{array}{l}\text { Father } \\
\text { education }\end{array}$} & Cannot read and write & 45 & 17.3 \\
\hline & Can Read and write & 55 & 21.3 \\
\hline & Grade 1 to 4 & 7 & 2.7 \\
\hline & Grade 5 to 8 & 12 & 4.6 \\
\hline & Grade 9 to 12 & 14 & 5.4 \\
\hline & College level and above & 127 & 48.8 \\
\hline \multirow{6}{*}{$\begin{array}{l}\text { Mother } \\
\text { education }\end{array}$} & Cannot read and write & 72 & 27.7 \\
\hline & Can Read and write & 32 & 12.3 \\
\hline & Grade 1 to 4 & 15 & 5.8 \\
\hline & Grade 5 to 8 & 8 & 3.1 \\
\hline & Grade 9 to 12 & 31 & 11.9 \\
\hline & College level and above & 102 & 39.2 \\
\hline \multirow{6}{*}{$\begin{array}{l}\text { Father } \\
\text { occupation }\end{array}$} & Daily laborer & 9 & 3.5 \\
\hline & Farmer & 91 & 35 \\
\hline & Civil servant & 107 & 41.2 \\
\hline & $\begin{array}{l}\text { Employed in private } \\
\text { business }\end{array}$ & 23 & 8.8 \\
\hline & Has private business & 28 & 10.8 \\
\hline & Others & 2 & 0.8 \\
\hline \multirow{6}{*}{$\begin{array}{l}\text { Mother } \\
\text { occupation }\end{array}$} & Daily laborer & 20 & 7.7 \\
\hline & Farmer & 81 & 31.2 \\
\hline & Civil servant & 75 & 28.8 \\
\hline & $\begin{array}{l}\text { Employed in private } \\
\text { business }\end{array}$ & 17 & 6.5 \\
\hline & Has private business & 55 & 4.6 \\
\hline & Others & 12 & 4.6 \\
\hline Family & $<500$ ETB & 28 & 10.8 \\
\hline monthly & $500-1500$ & 66 & 25.4 \\
\hline $\begin{array}{l}\text { income } \\
\operatorname{Min}=100\end{array}$ & $>1500$ & 129 & 49.6 \\
\hline $\begin{array}{l}\text { ETB } \\
\operatorname{Max}=9000\end{array}$ & Don't know & 37 & 14.2 \\
\hline
\end{tabular}

Table 3. Non sexual risk behaviors of respondents among Debre Markos University students, North West Ethiopia, 2014.

\begin{tabular}{llll}
\hline Variables & & Frequency & Percentage \\
\hline \multirow{3}{*}{ Smoke } & Never & 215 & 82.7 \\
cigarrate & Once or twice per week & 26 & 10 \\
& From time to time & 11 & 4.2 \\
& Daily & 8 & 3.1 \\
& Never & 187 & 71.9 \\
Chew chat & Once or twice per week & 24 & 9.2 \\
& From time to time & 19 & 7.3 \\
& Daily & 30 & 11.5 \\
Drink alcohol & Never & 153 & 58.8 \\
& Once or twice per week & 65 & 25 \\
\multirow{2}{*}{ Use drugs like } & From time to time & 29 & 11.2 \\
shisha/ hashish & Once or twice per week & 23 & 5 \\
Viewing & From time to time & 4 & 89.6 \\
pornographic & Yes & 85 & 8.8 \\
movies & No & 175 & 1.5 \\
\hline
\end{tabular}

\subsection{Sexual History of Respondents}

From 260 respondents, 116(44.6\%) had sex prior to the data collection period, while $144(55.4 \%)$ had never had sexual intercourse. Almost two third (64.7\%) of respondents start sex while during the age range of 16-19 years old. The mean and SD for the age at first sex was 18.28 and 2.04 years respectively. Seventy six percent of respondents who start sex 
said that boy/girl friend were their first sexual partner, followed by stranger, $17(14.7 \%)$ and teacher, $6(5.2 \%)$. The main reason mentioned by $69(59.5 \%)$ of respondents to start sex were fell in love followed by sex desire, marriage and to get money, 25(21.6\%), 9(7.8\%) and 6(5.2\%) respectively. From the total of 116 respondents who start sex, only $74(63.8 \%)$ have used condom during their first sex while the rest $42(36.2 \%)$ didn't use condom. From a total of 77 respondents who had sexual partner in the past 12 months prior to the data collection period, 57(74\%), 18(23.4\%), and (2(2.6\%) of respondents said that they had had one, 2-4 and more than five sexual partners respectively (Table 4).

\subsection{Factors Associated with Early Sexual Initiation}

Bivariate and multivariate analysis was conducted to determine factors associated with early sexual initiation, less than 18 years old. Accordingly on bivariate analysis factors which were found to be associated with the dependent variable at $95 \% \mathrm{CI}$ and $\mathrm{p}$ value less than 0.05 were; discussion on Sexual and Reproductive health issues with mother $(\mathrm{COR}=2.78,95 \% \mathrm{CI}=1.22-6.35)$, and Cigarrate smoking $(\mathrm{COR}=2.77, \quad 95 \% \mathrm{CI}=1.19-6.47) . \quad$ After computing for multivariate logistic regression three variables were found to be associated with sexual intitiation less than 18 years old.

Being a female were found to be 5.7 times more likely to initiate sexual intercourse before their 18th birthday than males $(\mathrm{AOR}=5.7,95 \% \mathrm{CI}=1.16-27.72)$ with $\mathrm{p}$-value of 0.03 . In addition respondents who discuss on sexual and reproductive health issues with their mother were less likely to initiate sexual intercourse before 18 years old. Those who didn't discuss on SRH with eir mother were times more likely to inititate sexual intercourse before 18 years old $(\mathrm{AOR}=$, $95 \% \mathrm{CI}=1.23-41.5)$ and $\mathrm{p}$-value of 0.02 . Respondents who smoke cigarrate were seven times more likely to involve in sexual initiation prior to their 18th birthday when compared with those who don't smoke cigarrate (AOR=7, $95 \% \mathrm{CI}=1.06-46.92$ ) and $\mathrm{p}$-value of 0.04 (Table 5).

Table 4. Sexual history of respondents among Debre Markos University students, North West Ethiopia, 2014.

\begin{tabular}{llll}
\hline Variables & & Frequency & Percentage \\
\hline Ever had sex & Yes & 116 & 44.6 \\
Age at first sex & No & 144 & 55.4 \\
Mean=18.28, SD $=$ & 14-15 years old & 11 & 9.5 \\
2.04 & 20-25 years old & 30 & 64.7 \\
& Boy/girl friend & 88 & 25.9 \\
Relation with first sex & Teacher & 6 & 75.9 \\
partner & Stranger & 17 & 5.2 \\
& Other & 14.7 \\
& Fall in love & 69 & 4.3 \\
& Sex desire & 25 & 59.5 \\
Reason for first sex & Marriage & 9 & 21.6 \\
& To get money & 6 & 7.8 \\
& Peer pressure, & 7 & 5.2 \\
Use of condom & rape, was drunk & & 6.1 \\
during first sex & Yes & 74 & 63.8 \\
Number of sexual & No & 42 & 36.2 \\
partners in the past 12 & 2-4 & 57 & 74 \\
months & $\geq 5$ & 18 & 23.4 \\
$*$ family member, & & 2 & 2.6 \\
neighbor & & & \\
\hline
\end{tabular}

Table 5. Bivariate and multivariate regression indicating factors associated with early sexual initiation among Debre Markos University students, North West Ethiopia, 2014.

\begin{tabular}{|c|c|c|c|c|c|c|}
\hline \multirow{2}{*}{ Variables } & & \multicolumn{2}{|l|}{ Age at first sex } & \multirow{2}{*}{ COR 95\%CI } & \multirow{2}{*}{ AOR 95\%CI } & \multirow{2}{*}{ P value } \\
\hline & & $<18$ years old & $>18$ years old & & & \\
\hline \multirow{2}{*}{ Sex } & Male & 47 & 40 & 1 & 1 & \\
\hline & Female & 19 & 10 & $1.6(0.67,3.87$ & $5.7(1.16,28.72)^{*}$ & $0.033 *$ \\
\hline \multirow{3}{*}{ Family monthly income } & $<500$ & 14 & 8 & 1 & 1 & \\
\hline & $500-1500$ & 19 & 14 & $0.78(0.26,2.35)$ & $0.55(0.07,4.61)$ & 0.585 \\
\hline & $>1500$ & 33 & 28 & $0.67(0.25,1.84)$ & $0.37(0.05,2.74)$ & 0.334 \\
\hline \multirow{4}{*}{ Living condition } & With Father and mother & 51 & 39 & 1 & 1 & \\
\hline & Either Mother or Father & 6 & 6 & $0.76(0.23,2.55)$ & $0.29(0.038,2.32)$ & 0.247 \\
\hline & Relatives/friends & 8 & 3 & $2(0.51,8.19)$ & $1.72(0.19,14.93)$ & 0.622 \\
\hline & Alone & 1 & 2 & $0.38(0.03,4.37)$ & $0.23(0.005,9.97)$ & 0.445 \\
\hline Discuss on & Yes & 37 & 39 & 1 & 1 & \\
\hline SRH with mother & No & 29 & 11 & $2.78(1.22,6.35)^{*}$ & $7.14(1.23,41.5)^{*}$ & $0.029 *$ \\
\hline Discuss on & Yes & 35 & 32 & 1 & 1 & \\
\hline SRH with Father & No & 31 & 18 & $1.57(0.74,3.34)$ & $1(0.23,4.45)$ & 0.996 \\
\hline \multirow{2}{*}{ Smoke cigarate } & Yes & 27 & 10 & $2.77(1.19,6.47)^{*}$ & $7(1.06,46.92)^{*}$ & $0.044 *$ \\
\hline & No & 39 & 40 & 1 & 1 & \\
\hline \multirow{2}{*}{ Chew chat } & Yes & 36 & 19 & $1.96(0.93,4.14)$ & $1.07(0.19,5.85)$ & 0.939 \\
\hline & No & 30 & 31 & 1 & 1 & \\
\hline \multirow{2}{*}{ Drink alcohol } & Yes & 38 & 24 & $1.5(0.7,3.08)$ & $1.3(0.29,5.7)$ & 0.742 \\
\hline & No & 28 & 26 & 1 & 1 & \\
\hline \multirow{2}{*}{ Have boy/girl friend } & Yes & 56 & 39 & 1 & 1 & \\
\hline & No & 10 & 11 & $0.63(0.24,1.64)$ & $0.58(0.12,3.21)$ & 0.532 \\
\hline \multirow{2}{*}{ Viewing of pornographic movies } & Yes & 29 & 20 & 1 & 1 & \\
\hline & No & 37 & 30 & $0.85(0.4,1.79)$ & $2.4(0.49,11.97$ & 0.275 \\
\hline \multirow{2}{*}{ Attitude towards sex } & Unfavorable & 34 & 27 & 1 & 1 & \\
\hline & Favorable & 32 & 23 & $1.1(0.53,2.31)$ & $0.73(0.24,2.19)$ & 0.573 \\
\hline
\end{tabular}




\section{Discussion}

This study was conducted to assess the age at sexual initiation and its associated factor among Debre Markos University students. accordingly this study showed that $44.6 \%$ of respondents had had sexula intercourse. Similar study conducted in North East Ethiopia showed that the percentage of youths who ever had sex was $51.3 \%$, which is higher than the current study finding. Possible explanations could be due to the difference in sociodemographic variables and the fact that the previouse study assessed youths from urban and rural areas while the current study included university students, which is believd to have a better sexual and reproductive health knoweledge [3]. In addition, a study conducted among youths in South west Ethiopis showed that $72.1 \%$ of youths had ever had sex, the difference could be explained by the above reasons [14].

The current study also found that, $66(56.9 \%)$ had had first sexual intercourse before their $18^{\text {th }}$ birthday. The trends and differentials in Sub Saharan countries showed that the precentage of early sexual initiation befor 18 years old for kenya is $57 \%$, and Senegal $52 \%$ which is in comparable with the current finding [22]. The mean and median age for first sexual initiation of this study was 18.28 and 18 years old which is slightly highly higher than studies conducted in South west Ethiopia [17.07], North East Ethiopia (16 years for rural and 17 years for urban) [3, 14]. The reason for such difference could be due to the study population, because previous studies included rural youths in which there is early marriage which was one of the main reasons for first sexual intercourse for most of rural youths $[3,14,23,24]$. But, the current study finding is in comparable with previous study conducted in Thailand (median ages of 17 and 18 for male and female) [11].

Factors which were found to be associated with early sexual initiation were sex, discussion with mother and cigarate smoking. Females were 5.7 times more likely to start sexual initiation early when compared with males. This can be because females face lots of pressure from their friend and they lack skill of negotiation in sexual relationships and due to the influence of early marriage among females. This finding is similar with other studies conducted in Alamata, North East Ethiopia, and Zimbabwe [3, 21, 25].

In addition, those students who had no discussion with their mother on sexual and reproductive health issues were more than seven time more likely to initiate sexual intercourse before their $18^{\text {th }}$ birthday than those who discuss with their mother. This could be because parent adolescent communication on sexual and reproductive health issues is important in improving the knowledge of young peoples on HIV//AIDS, sexuality and its consequence. At the same time when mothers communicate on the importance of virginity and on the risks of initiating sexual intercourse. And having comprehensive knowledge on HIV is preventable against early sexual initiation [14]. Similar findings were observed in other study. For example a study conducted in North East Ethiopia showed that being less connected with parents to be associated with early sexual initiation [3].
The current study also showed that young peoples who use substance (i.e cigarate smoking) were more likely to start sexual initiation early (less than 18 years old). This could be because of the effect of the substance on the judgment of the young peoples whether to initiate sexual practice early or not [21]. Similar finding were observed in a study conducted in Thailand [11].

\section{Conclusion}

More than one third of respondents had had sexual intercourse. from these; more than half of study participants were involved in early sexual intercourse before 18 years old. Factors which were found to be associated with early sexual intercourse (18 years old) were being female, lack of discussion on sexual and reproductive health issues with their mother and cigarate smoking.

\section{Recommendation}

One of the mechanisms to reduce the progress of HIV/AIDS is delaying the initiation of sexual intercourse. This can be achieved through awareness creation for both male and female young peoples through the use of religious leaders, school teachers and parents after providing the necessary training on sexual and reproductive health issues. In addition young peoples should be encouraged to discuss with their parents on sexual and reproductive health through the use of reproductive health centers and emphasis should be given for adolescents who use drugs like cigarate smoking.

\section{Abbreviations}

SRH: Sexual and reproductive Health; DMU: Debre Markos University; EDHS: Ethiopian Demographic and Health Survey.

\section{Acknowledgements}

We would like to acknowledge to Debre Markos University, College of Medicine and Health Science, to data collectors and study participants.

\section{References}

[1] Carlos M., Néia S., Ivan F., Simone G. Factors associated with sexual initiation and condom use among adolescents on Santiago Island, Cape Verde, West Africa. Cad. Saúde Pública, Rio de Janeiro, 25(9):1969-1980, set, 2009.

[2] FHI, USAID: Youth Net Assessment Team: Assessment of Youth Reproductive Health Programs in Ethiopia. Addis Ababa, Ethiopia: FHI and USAID; 2004.

[3] Fekadu M., Alemayehu W. Age at sexual initiation and factors associated with it among youths in North East Ethiopia. Ethiop. J. Health Dev.2009; 23(2):154-162. 
[4] PAV G, ORC M, Aklilu K, Hailom B. Youth Reproductive Health in Ethiopia. Addis Ababa; November 2002.

[5] Habtamu Mellie Bizuayehu, Direslgne Misker Abyu, Hailu Fekadu Demessie. Assessment of Time of Sexual Initiation and Its Associated Factors among Students in Northwest Ethiopia. Science Journal of Public Health.Vol. 3, No. 1, 2015, pp. 10-18. doi: 10.11648/j.sjph.20150301.13

[6] Dorothy S. Access to sexual and reproductive health for young people: Bridging the disconnect between rights and reality. International Journal of Gynecology and Obstetrics. 2009; 106(2): 132-136.

[7] WHO/UNFPA/UNICEF. Programming for adolescent health and development. Geneva, 1999.

[8] Ethiopian Demographic and Health Survey 2011. Central Statistical, Addis Ababa, Ethiopia ICF International Calverton, Maryland, USA; 2012.

[9] Mulu Tilahun Yigzaw, Alemayehu Worku Yalew, Alemayehu Bogale Mesfin, Agumasie Semahegn Demisie. Sexual Initiation and Factors Associated with it among Addis Ababa University Undergraduate Students, Addis Ababa, Ethiopia. American Journal of Health Research. Vol. 2, No. 5, 2014, pp. 260-270. doi: 10.11648/j.ajhr.20140205.17

[10] Kssaye Z:Sexual experiences and their correlates among Jimma University Students, Jimma, Ethiopia.Ethiopian J Health Sci 2005,15(1):1-17.

[11] Alice L, Peter K, Richard A, Chomnad M, Philip A, Supaporn J, Wat U, Frits V. Sexual Initiation, Substance Use, and Sexual Behavior and Knowledge Among Vocational Students in Northern Thailand. International Family Planning Perspectives. September 2006; 32(3): 126 - 135.

[12] Derege K, Atalay A, Getnet M:Khat and alcohol use and risky sex behavior among in-school and out-of-school youth in Ethiopia. BMC Publ Health2005,5:109.

[13] Adesegun O, Robert W: Predictors of early sexual initiation among a nationally representative sample of Nigerian adolescents.BMC Publ Health2008,8:136.

[14] Marelign Tilahun and Gistane Ayele. Factors associated with age at first sexual initiation among youths in Gamo Gofa, South West Ethiopia: a cross sectional study. BMC Public Health2013,13:622.
[15] Augustine Ankomah, Fatima Mamman-Daura, Godpower Omoregie, Jennifer Anyanti. Reasons for delaying or engaging in early sexual initiation among adolescents in Nigeria. Adolescent Health, Medicine and Therapeutics 2011:2 75-84.

[16] Mallika A, Laila G, Savita K, Shireen J, Bela G. Correlates of Premarital Relationships Among Unmarried Youth in Pune District, Maharashtra, India. International Family Planning Perspectives. 2007; 33(4): 150-159.

[17] Debre Markos town. [Internet]. [Cited 2014 March 22]. Available from: http://en.wikipedia.org/wiki/Debre_Marqos.

[18] Brief History of Debre Markos University. [Internet]. [Cited 2014 March 22]. Available from: http://web.dmu.edu.et/test-dmu-site/index.php/about.

[19] Melisew M. Premarital sexual practice and perception of high risk of HIV/AIDS among school adolescents in Injibara town, Awi zone. [Msc thesis]. Addis Ababa University; July 2008.

[20] Dessalegn W. Assessment of Premarital Sexual Practice and factors contributing to premarital sex among high School Adolescents in Nekemte Town, East Wollega, Oromia regional state. [Mph thesis]. Addis Ababa University; 2006.

[21] Getachew MK, Emebet BW\& Nurilign AM. Prevalence of Premarital Sexual Practice and Associated Factors among Alamata High School and Preparatory School Adolescents, Northern Ethiopia Global Journal of Medical research: $\mathrm{k}$ Interdisciplinary Volume 14 Issue 3 Version 1.0 Year 2014. Page 8-16.

[22] Neeru Gupta and Mary Mahy. Sexual Initiation Among Adolescent Girls and Boys:Trends and Differentials in Sub-Saharan Africa. Archives of Sexual Behavior, Vol. 32, No. 1, February 2003, pp. 41-53 (C ${ }^{\circ} 2003$.

[23] Central Statistical Agency [Ethiopia] and ORC Macro:Ethiopia Demographic and Health Survey 2010.Addis Ababa, Ethiopia: Central Statistical Agency and ORC Macro; 2011.

[24] Mitike M, Yemane B, Bernt L: Traditional values of virginity and sexual behaviour in rural Ethiopian youth: results from a cross-sectional study. BMC Publ Health2008,8:9.

[25] Cremin I, Mushati P, Hallett T, Mupambireyi Z, Nyamukapa C, Gamett $\mathrm{G}$ et al. Measuring trends in age at first sex and age at marriage in Manicaland, Zimbabwe. Sex Transm Infect. 2009; 85(Suppl I): 34-40. 